\title{
Screening for Obstructive Sleep Apnea is Imperative for Diabetes Mellitus Patients
}

\author{
Saumy Johnson* \\ Assistant Professor and Vice Chair, Department of Respiratory Therapy Sciences, Inaya Medical College, Saudi Arabia
}

Submission: February 01, 2018; Published: February 12, 2018

*Corresponding author: Saumy Johnson, Assistant Professor and Vice Chair, department of Respiratory Therapy Sciences, Inaya Medical College, Riyadh, KSA, Saudi Arabia, Email: sjohnson@inaya.edu.sa

\section{Introduction}

Diabetes mellitus a metabolic syndrome affecting millions of population worldwide. World Health Organization (WHO) estimated it to be nearly 347 million and around $90 \%$ of them have type 2 diabetes. Quality of life is considered as a good indicator in patients to predict their wellbeing and it is noteworthy to know that DM patients due to various symptoms and impact of the disease have exhibited poor quality of life $[1,2]$.

\section{Obstructive Sleep Apnea}

Obstructive Sleep Apnea (OSA) is a sleep disorder characterized by daytime somnolence, snoring and unrefreshing sleep. OSA patients may have partial or complete obstruction of the upper airway which leads to repeated awakening and poor quality of sleep. Oxygen saturation is reduced and $\mathrm{CO}_{2}$ levels are increased due to frequent apneas. Polysomnography is the gold standard diagnostic tool to diagnose OSA. An Apnea Hypopnea Index $\geq 5$ /hour is considered positive for OSA. AHI 5-10/hr is considered mild OSA, Moderate: AHI $\geq 15$, but $<30$ per hour and Severe OSA is: AHI $\geq 30$ per hour [3].

\section{Use of CPAP}

A recent meta-analysis by Wang $X$ et al. [4] on a cohort of 5953 participants, who were followed up for 16 years showed that Moderate to Severe OSA was associated with increased risk of Diabetes (RR 1.63; 95\% confidence interval (CI): 1.09$2.45)$, when compared with patients does not have OSA. This meta-analysis of six prospective cohort studies including a total of, with follow-up periods of 2.7-16 years, and 332 incident cases of type 2 diabetes, showed that moderate-severe OSA was associated with a greater risk of diabetes as compared with the absence of OSA. Sensitivity analyses yielded similar results. For subjects with mild OSA, as compared with those without OSA, the pooled RR of developing type 2 diabetes was 1.22 (95\% CI: 0.91-1.63). This appears to be an independent risk factor for the development of diabetes [4]. There are different treatment options for patients diagnosed as OSA. Weight reduction, CPAP use, position changes and Upper airway surgeries. Continuous Positive Airway Pressure (CPAP) is the standard treatment for OSA currently. In Diabetes, controversy exists if the CPAP therapy gives a positive effect on the glucose metabolism or not. It also depends on the BMI and the level of CPAP. Large RCTs are needed to find out the metabolic effects of CPAP. There may be responders and non- responders to CPAP therapy, it is important to find out the reasons behind this phenomenon and to link it to the phenotype variability. This information may be vital in the clinical management of patients with OSA who have Diabetes or prediabetes [5].

\section{Importance of screening}

OSA in DM patients is still under diagnosed and a routine screening method at hospitals and clinics will help to identify the patients who are risk and will enable early and better treatment. Screening questionnaires that are available include the Epworth Sleepiness Scale (ESS), the STOP Questionnaire (Snoring, Tiredness, Observed Apnea, High Blood Pressure), STOP-Bang Questionnaire (STOP Questionnaire plus BMI, Age, Neck Circumference, and Gender), Berlin questionnaire and the Wisconsin Sleep Questionnaire [6]. Multivariable Apnea Prediction (MAP) Index includes questions on frequency of OSA symptoms (snoring or gasping, loud snoring and breathing stops, choke or struggle for breath) body mass index (BMI), age, and sex [7]. Screening with MVAP followed by an in-home sleep study may have ability for correctly differentiating persons in the common population with the probability to have OSA [8].

\section{References}

1. Kara B, Kılıç Ö (2015) Predictors of poor sleep quality and excessive daytime sleepiness in Turkish adults with type 2 diabetes. J ClinNurs 24(9-10): 1436-1439.

2. Ozturk ZA, Yesil Y, Kuyumcu ME, Savas E, Uygun O, et al. (2014) Association of depression and sleep quality with complications of type 


\section{Current Research in Diabetes \& Obesity Journal}

2 diabetes in geriatric patients. Aging Clin Exp Res 27(4): 533-538.

3. Sateia MJ (2014) International classification of sleep disorders-third edition: highlights and modifications. Chest 146(5): 1387-1394.

4. Wang X, Bi Y, Zhang Q, Pan F (2013) Obstructive sleep apnoea and the risk of type 2 diabetes: a meta-analysis of prospective cohort studies. Respirology 18(1): 140-146.

5. Pamidi S, Tasali E (2012) Obstructive sleep apnea and type 2 diabetes: is there a link? Front Neurol 3: 126
6. Abrishami A, Khajehdehi A, Chung F (2010) A systematic review of screening questionnaires for obstructive sleep apnea. Can J Anaesth 57(5): 423-438.

7. Mehrizi AK, Aminian O (2016) Diagnostic accuracy of the Multivariable Apnea Prediction (MAP) index as a screening tool for obstructive sleep apnea. Journal of Sleep Sciences 1(1): 8-12.

8. Jonas DE, Amick HR, Feltner C, Palmieri Weber RP, Arvanitis M, et al (2017) Screening for obstructive sleep apnea in adults: an evidence review for the U.S. preventive services task force JAMA 317(4): 415433.

Your next submission with Juniper Publishers will reach you the below assets

- Quality Editorial service

- Swift Peer Review

- Reprints availability

- E-prints Service

- Manuscript Podcast for convenient understanding

- Global attainment for your research

- Manuscript accessibility in different formats

( Pdf, E-pub, Full Text, Audio)

- Unceasing customer service

Track the below URL for one-step submission https://juniperpublishers.com/online-submission.php 